City University of New York (CUNY) CUNY Academic Works

2017

\title{
Content Analysis of Data Science Graduate Programs in the U.S.
}

Duo Li

Shenyang City University

Elizabeth Milonas

CUNY New York City College of Technology

Qiping Zhang

Long Island University

\section{How does access to this work benefit you? Let us know!}

More information about this work at: https://academicworks.cuny.edu/ny_pubs/798

Discover additional works at: https://academicworks.cuny.edu

This work is made publicly available by the City University of New York (CUNY).

Contact: AcademicWorks@cuny.edu 


\section{Content Analysis of Data Science Graduate Programs in the U.S.}

\section{Dr. Duo Li, Shenyang City University}

Dr. Duo Li is the chief research scientist of Green Island Hotel Industry Research Institute of Shenyang City University. Duo Li is the member of ASIST\&T and his research interests are focusing on HumanComputer-Interaction, Big Data, Data Analytics, Social Networking, and Hospitality Management.

QUALIFICATIONS: Skilled professional experienced in big data, data analysis, bibliometric, social networking sites, statistic software, and online learning system. Full skilled in establishing, operating, and maintaining online course on Blackboard. Educated in data visualization, multidimensional scaling analysis, and human computer interaction. Well versed in Camtasia, and graphics processing software.

EDUCATION: Doctor of Philosophy in Information Studies, May 2017. LONG ISLAND UNIVERSITY, POST CAMPUS, Brookville, NY

Master of Science, Management Engineering, January 2010. LONG ISLAND UNIVERSITY, POST CAMPUS, Brookville, NY

Bachelor of Science, Automotive Engineering, July 2007. BEIJING INSTITUTE OF TECHNOLOGY, Beijing, P.R. China

\section{Dr. Elizabeth Milonas, New York City College of Technology}

Elizabeth Milonas is an Assistant Professor with the Department of Computer Systems at New York City College of Technology -City University of New York (CUNY). She currently teaches relational and non-relational database theory and practice and Data Science courses to undergraduates in the Computer Systems Major. Her research focuses on three key computer areas: Web: research on the mechanisms used to organize big data in search result pages of major search engines, Ethics: techniques for incorporating ethics in computer curriculum specifically in data science curriculum and programs/curricula: evaluating Data Science programs in the US and China.

\section{Dr. Qiping Zhang, Long Island University}

Dr. Qiping Zhang is an Associate Professor in the Palmer School of Library and Information Science at the C.W. Post Campus of Long Island University, where she also serves as director of the Usability Lab. Dr. Zhang holds a Ph.D. and an M.S. in information and library studies from the University of Michigan, Ann Arbor, and an M.S. and a B.S. in cognitive psychology from Peking University in Beijing, China. Prior to joining Long Island University in 2006, she worked at Drexel University, IBM Waterson Research Center, and Institute of Psychology at Chinese Academy of Science.

Dr. Zhang's general research areas are human-computer interaction (HCI), knowledge management (KM), social informatics and distance learning. Her primary interests lie in the areas of computer-supported cooperative work (CSCW) and computer-mediated communication. Specifically, she is interested in facilitating productive collaborations of individuals who are geographically and culturally distributed. Dr. Zhang has published numerous papers in the areas of HCI, CSCW, KM, social informatics and related disciplines. 


\section{Content Analysis of Data Science Graduate Programs in the U.S.}

\section{INTRODUCTION}

Data science is an emerging academic field [1], which has its origins in Big Data and Cloud Computing and other complex science-related domains. Data Science is concerned with managing large and complex data and the use of data analytics technologies [1]. The three pillars of data science are data, technology, and people, and the three critical areas of data science are analytics, infrastructure, and data curation [2]. Data science is defined [3] as "an emerging area of work concerned with the collection, preparation, analysis, visualization, management, and preservation of extensive collections of information [3]. Data science programs emphasize the implementation of tools, techniques, and visualization strategies, while data analytics programs emphasize case studies and the evolution of tools [4].

Data science experts are needed in virtually every job sector, not just in technology. KDnuggest, a leading website on Big Data [5], reports that "Data scientists are highly educated-88 percent have at least a master's degree and 46 percent have PhDs-and while there are notable exceptions, a very strong educational background is usually required to develop the depth of knowledge necessary to be a data scientist." In a study conducted by Bukhari (2020), a content analysis of the 30 Master's Degree curricula in Data Science, revealed that schools that offer these programs are diverse: business, computer science, and science schools.

The objective of the study is to survey U.S. graduate programs in data science to understand the current situation of data science graduate education in the U.S.. The comparison of such program analyses with corresponding accreditation criteria will allow us to understand the stage of these programs, whether they are still in infancy or if they are on the path to maturity.

\section{LITERATURE REVIEW}

In a study conducted [6], content analysis of the 30 Master's Degree curricula in Data Science, revealed that schools that offer these programs are diverse. They include and are not limited to Business, Computer Science, and Sciences Schools. The study [6] showed that on an average, Data Science(DS) master's programs require 18.3 credits and 9.7 courses to complete the core requirements. However, there are inconsistencies in terms of the requirement across the 30 programs reviewed in this study [6]. The study results showed that Data Science related courses such as data retrieval, database management, data mining and data visualization are in the top core offerings, followed by analytical courses, followed by capstone/internship/project/thesis, followed by statistics/probability/math, followed by programming, followed by business intelligence/NLP/Machine learning. Least on the list is communication /privacy /professionalism /ethics.

In an earlier study [7], content analysis of a total of 59 ALA-accredited Library Master's programs in North America listed on the ALA website (www.ala.org/accreditedprograms/directory) in December 2015 were evaluated. Each institution's course offering documentation on their websites, such as the current course catalog and course description database, were reviewed to identify data-related programs and courses. The goal of the research was to identify current trends 
in library and information science education in response to the rising demand for data professionals [7]. Chu et al (2017) proposed that iSchools should make contributions based on the traditional and modern advantages of data science-related fields, such as information organization and access, information management, information preservation, and information science research. Experts can discuss and establish a more precise definition, scope and data flow of data science. Compile a list of fundamental principles, skills, and toolsets necessary for data scientists to help current and future information experts assess their level and find courses and programs that suit their level, interests, and career plans. In order to improve the quality and effectiveness of the program, organizations should strive to convene faculty and staff from different disciplines that specifically address the different knowledge and skills required for data science (for example, statistics, computer science, information science, business and marketing, metadata, digital library, institutional database) [8].

\section{METHOD}

The goal of this research study is to understand the overview of master-level data science programs in the U.S. to find out the main core data science courses, and the program structure evolutions from related domains of data science. In the past, people's research on data, except in traditional mathematics and statistics departments, was the most common business data application. Due to the rise of the Internet, business data research has also progressed to the field of business intelligence. Still, according to EMC surveys, data science currently accounts for an increasing proportion of degree education, especially graduate education, than business intelligence [9]. The research questions explored in this study are:

RQ1: What is the current status of data science graduate programs in the United States?

RQ2: What is the development direction of the data science graduate program?

\subsection{Operational Definition}

In order to more accurately collect data related to data science programs, the terms "data science", "data analytics", and "analytics"related to graduate programs, were unified into "data science alternative" programs.

\subsection{Data Sources}

In this study, "Data Science" and "Data Analytics" were used as search terms in order to collect the most Data Science graduate programs data. Additionally, data found in the following websites was used to create the list of targeted master-level data science programs for this paper.

- 311 Masters Programs in Data Science: https://www.masterstudies.com/Masters-Degree/Data-Science/

- Best 23 Schools With Data Science Master’s Programs in 2021: https://www.mastersindatascience.org/schools/23-great-schools-with-masters-programsin-data-science/

- Masters Degrees in USA (Data Science): https://www.findamasters.com/masters-degrees/usa/?400120\&Keywords=data\%20science

\subsection{Datasets}

A total of 442 graduate Data Science programs were initially crawled, however, only 228 programs were evaluated for this study. 214 graduate programs were excluded due to the following: 
- There are two or more very similar data science subjects in the same major in the same university or college, and only the most relevant data science program was used.

- The program name indicates data science curricula however, after close examination, the core curricula is not data science related.

- Program changes or the official webpage cannot be accessed.

- Data science program jointly carried out by multiple universities, only one of the universities was used in this study.

\subsection{Program Profiles}

The following program profile information was collected from college and university websites, department webpages, and course descriptions.

College or university name, school name, type of institution; Department information including department name, degree, and major name; Graduate program credit information such as total number of minimum required credits for the degree, course delivery type information as online, campus or blended; Geographic information was collected as well, including university location (city, and state).

\subsubsection{Department/School Clusters}

- Some of the colleges examined did not have any department names associated with the Data Science Degree. In these cases, the school name was used.

- The departments or school names were examined and nine clusters were created: 1)Arts \& Science, 2)Business. 3)Computer Science, 4)Data Science, 5) Engineering, 6)Health, 7)Information Science and Technology, 8)Interdisciplinary, and 9)Math/Statistics.

- These department or school clusters were generated for analysis purposes as it is more effective to analyze data based on nine department or school clusters as opposed to over a hundred department or school names. The department or school names were mapped to these clusters as shown in table 1. Department or school names that were the same for more than one college or university are only shown once for the purpose of this table.

Table 1: Department or School Cluster Mapping

\begin{tabular}{ll}
\hline Combined & Dept.\& School \\
\hline College of Arts and Sciences & Arts \& Science \\
Graduate School of Arts \& Sciences & Arts \& Science \\
Krieger School of Arts \& Sciences & Arts \& Science \\
College of Arts and Sciences & Arts \& Science \\
Liberal Arts and Sciences & Arts \& Science \\
Kogod School of Business & Business \\
Business & Business \\
College of Business & Business \\
Graduate School of Business & Business \\
Mihaylo College of Business and Economics & Business \\
College of Business and Public Administration & Business \\
School of Business \& Technology & Business \\
Business and Information Systems & Business \\
Helzburg School of Management & Business
\end{tabular}


Culverhouse College of Commerce

School of Computing, Informatics, and Decision Systems Engineering

Department of Computer Science and Information Technology

MET Computer Science Department

College of Computing and Digital Media

School of Physics, Astronomy, and Computational Sciences

College of Computer and Information Sciences

Department of Computer Science

Graduate Programs in Software

Data Science Institute

School of Digital Science

NYU Center for Data Science

Institute for Data Science

Data Science

The Statistics and Data Science Department

Case School of Engineering

College of Engineering, Computing and Applied Sciences

Engineering for Professionals

School of Engineering, Technology and Media

Engineering

College of Health Professions

Lewis's Department of Biology

Feinberg School of Medicine

College of Osteopathic Medicine

School of Medicine: Department of Biomedical Informatics

Health Information Management Department (College of Health Professions)

College of Science and Technology

Center for Information Systems and Technology (CISAT)

College of Computing and Informatics with support from Drexel University's

Department of Computer Science and Information Systems

Computer and Information Science department

School of Computing and Information Systems

School of Communication and Information

Wesley J. Howe School of Technology Management

College of Information Studies

College of IS\&T

College of Professional \& Continuing Studies

Interdisciplinary

Steinhardt School of Culture, Education, and Human Development: D

College of Professional Studies

School of Economic, Political and Policy Sciences

Graham School of Continuing Liberal and Professional Studies

Harris School of Public Policy \& Computer Science Department

College of Computer, Mathematical, and Natural Sciences

Department of Biostatistics and Medical Informatics School of Medicine and Public Health
Business

Computer Science

Computer Science

Computer Science

Computer Science

Computer Science

Computer Science

Computer Science

Computer Science

Data Science

Data Science

Data Science

Data Science

Data Science

Data Science

Engineering

Engineering

Engineering

Engineering

Engineering

Health

Health

Health

Health

Health

Health

Info Science and Technology Info Science and Technology Info Science and Technology Info Science and Technology Info Science and Technology Info Science and Technology Info Science and Technology Info Science and Technology Info Science and Technology Info Science and Technology Interdisciplinary Interdisciplinary Interdisciplinary Interdisciplinary Interdisciplinary Interdisciplinary Interdisciplinary Interdisciplinary

Interdisciplinary 
Graduate School

Department of Applied Statistics \& Operations Research/Department of Math Department of Statistics and Biostatistics

Department of Mathematics and Statistics

Mathematics
Interdisciplinary

Math/Statistics

Math/Statistics

Math/Statistics

Math/Statistics

\subsubsection{Major Clusters}

The majors were examined, and 11 clusters were created: 1) Big Data, 2) Biomedical, 3) Business Analytics, 4) Business Intelligence, 5) Computer Science, 6) Data Analytics, 7) Data Science, 8) Health Informatics, 9) Information Science and Technology 10) Math/Statistics, and 11) Public Policy. These major clusters were generated for analysis purposes as it is more effective to analyze data based on eleven major clusters as opposed to over a hundred major names.

The major names were mapped to these clusters, as shown in table 2. Major names that were the same for more than one college or university data science program are only shown once for the purpose of this table.

Table 2: Major Clusters Mapping

\begin{tabular}{|c|c|}
\hline Major & Major-Clustered \\
\hline Big Data Systems & Big Data \\
\hline Biostatistics & Biomedical \\
\hline Master of Science in Bioinformatics & Biomedical \\
\hline Bioinformatics & Biomedical \\
\hline Computational Biology & Biomedical \\
\hline Biostatistics and Data Science & Biomedical \\
\hline Business Analytics & Business Analytics \\
\hline Master of Science in Business Analytics & Business Analytics \\
\hline Online MBA in Business Analytics & Business Analytics \\
\hline Business Intelligence and Analytics & Business Analytics \\
\hline $\begin{array}{l}\text { Master of Business And Science Degree in Analytics - Discovery } \\
\text { Informatics \& Data Sciences }\end{array}$ & Business Analytics \\
\hline Management Science-Business & Business Analytics \\
\hline Strategic Marketing & Business Intelligence \\
\hline Master of Business Administration & Business Intelligence \\
\hline Master of Science in Business Intelligence and Analytics & Business Intelligence \\
\hline Marketing & Business Intelligence \\
\hline Dual MBA Degrees & Business Intelligence \\
\hline Computer Science & Computer Science \\
\hline MS in Computational Science & Computer Science \\
\hline Computer Science with concentration in Data and Knowledge Systems & Computer Science \\
\hline Computing (Machine Learning) & Computer Science \\
\hline Analytics & Data Analytics \\
\hline M.S. in Strategic Analytics & Data Analytics \\
\hline Master of Science in Applied Analytics & Data Analytics \\
\hline MA in Data Analytics \& Applied Social Research & Data Analytics \\
\hline MS in Data Analytics Engineering & Data Analytics \\
\hline Data Analytics and Business Computing & Data Analytics \\
\hline Social Data Analytics and Research & Data Analytics \\
\hline
\end{tabular}


Master of Decision Analytics

Data Science

Applied Data Science

Statistics-Data Science

Data Mining

Master in Interdisciplinary Data Science

Data Science and Analytics

Master in Data Science for Public Policy

Complex Systems and Data Science

Communication Data Science

Spatial Data Science

Statistics and Data Science

Health Informatics

Master of Science in Health Care Informatics

Information Systems

Master of Science in Computer Information Systems Online (Data

Analytics Concentration)

Library and Information Science

Master of Science Degree in Integrated Geospatial Technology

MS in Data and Information Management

Information Systems Management

Information Quality Program

Professional Master of Information Systems

Library and Information Science

Information Technology

Applied Statistics

Statistical Science

Statistics

M.S. in Statistical Computing Data Mining Track

Government Analytics

Public Informatics

Public Policy Data Science
Data Analytics

Data Science

Data Science

Data Science

Data Science

Data Science

Data Science

Data Science

Data Science

Data Science

Data Science

Data Science

Health Informatics

Health Informatics

Info Science and Technology

Info Science and Technology

Info Science and Technology

Info Science and Technology

Info Science and Technology

Info Science and Technology

Info Science and Technology

Info Science and Technology

Info Science and Technology

Info Science and Technology

Math/Statistics

Math/Statistics

Math/Statistics

Math/Statistics

Public Policy

Public Policy

Public Policy

\subsubsection{U.S. Geographical Clusters}

According to the United States Census Bureau's regional division, the following four regions are identified: 1) Northeast; 2) Midwest; 3) South; and 4) West (See Table 3).

Table 3: United States Geographical Regions

\begin{tabular}{|lc|lc|}
\hline \multicolumn{1}{|c|}{$\begin{array}{c}\text { Region 1 } \\
\text { (Northeast) }\end{array}$} & $\begin{array}{c}\text { State } \\
\text { abbr. }\end{array}$ & \multicolumn{1}{c|}{$\begin{array}{c}\text { Region 3 } \\
\text { (South) }\end{array}$} & $\begin{array}{c}\text { State } \\
\text { abbr. }\end{array}$ \\
Maine & $\mathrm{ME}$ & Delaware & DE \\
New Hampshire & $\mathrm{NH}$ & Maryland & MD \\
Vermont & $\mathrm{VT}$ & District of Columbia & DC \\
Massachusetts & $\mathrm{MA}$ & Virginia & VA \\
Rhode Island & $\mathrm{RI}$ & West Virginia & WV \\
Connecticut & $\mathrm{CT}$ & North Carolina & NC \\
New York & $\mathrm{NY}$ & South Carolina & SC
\end{tabular}




\begin{tabular}{|c|c|c|c|}
\hline Pennsylvania & $\mathrm{PA}$ & Georgia & GA \\
\hline New Jersey & NJ & Florida & FL \\
\hline $\begin{array}{c}\text { Region } 2 \\
\text { (Midwest) }\end{array}$ & $\begin{array}{l}\text { State } \\
\text { abbr. }\end{array}$ & Kentucky & KY \\
\hline Wisconsin & WI & Tennessee & $\mathrm{TN}$ \\
\hline Michigan & MI & Mississippi & MS \\
\hline Illinois & IL & Alabama & $\mathrm{AL}$ \\
\hline Indiana & IN & Oklahoma & OK \\
\hline Ohio & $\mathrm{OH}$ & Texas & $\mathrm{TX}$ \\
\hline North Dakota & ND & Arkansas & AR \\
\hline South Dakota & SD & Louisiana & LA \\
\hline Nebraska & $\mathrm{NE}$ & $\begin{array}{c}\text { Region } 4 \\
\text { (West) }\end{array}$ & $\begin{array}{l}\text { State } \\
\text { abbr. }\end{array}$ \\
\hline Kansas & KS & Idaho & ID \\
\hline Minnesota & $\mathrm{MN}$ & Montana & MT \\
\hline Iowa & IA & Wyoming & WY \\
\hline \multirow[t]{10}{*}{ Missouri } & MO & Nevada & NV \\
\hline & & Utah & UT \\
\hline & & Colorado & $\mathrm{CO}$ \\
\hline & & Arizona & $\mathrm{AZ}$ \\
\hline & & New Mexico & NM \\
\hline & & Alaska & AK \\
\hline & & Washington & WA \\
\hline & & Oregon & OR \\
\hline & & California & CA \\
\hline & & Hawaii & HI \\
\hline
\end{tabular}

Source from: https://www.census.gov/geographies/reference-maps/2010/geo/2010-census-regions-and-divisionsof-the-united-states.html

\subsection{Data Science Competencies}

\section{ACM Report Competencies}

- The data science competencies used in this study are based on the findings of the Association for Computing Machinery (ACM) Data Science Task Force. The Association for Computing Machinery (ACM) is a society that focuses on education, research and learning. ACM provides resources to its members, including publications, conferences, professional resources, and digital libraries.

- The mission of the ACM Data Science Task Group is to provide tasks in 2017 and guidance on specific capabilities in data science computing for undergraduate courses. In 2018, the task force designed two surveys to collect information on key data science computing competencies from academia and industry. In 2019, they demonstrated these competencies at the conference and collected opinions and suggestions from the data science community. Throughout 2019 and 2020, the task force continued to solicit opinions and suggestions from the data science community, and in 2021 will publish the revised list of competencies in the January 2021 " Computing Competencies for Undergraduate Data Science Curricula Report". 
The undergraduate program is the foundation of the graduate program, and the graduate program should also continue the framework system of the undergraduate curriculum.

- The eleven Data Science competencies identified in the 2021 ACM report are listed in Table 4 , and it identifies the sub-topics for each competency as well.

Table 4: Sub-topic Identified in the ACM Data Science Task Force Report

\begin{tabular}{|c|c|}
\hline \multicolumn{2}{|c|}{ ACM Data Science Task Force Report Competencies } \\
\hline $\begin{array}{l}1 \text { Analysis and Presentation } \\
\text { - Foundational considerations } \\
\text { - Visualization } \\
\text { - User-centered design } \\
\text { - Interaction design } \\
\text { - Interface design and development }\end{array}$ & $\begin{array}{l}7 \text { Data Privacy, Security, Integrity, and Analysis for } \\
\text { Security } \\
\text { - Data privacy } \\
\text { - Data security } \\
\text { - Data integrity } \\
\text { - Analysis for security }\end{array}$ \\
\hline $\begin{array}{l}2 \text { Artificial Intelligence } \\
\text { - General } \\
\text { Knowledge representation and reasoning - logic based } \\
\text { Knowledge representation and reasoning - probability based } \\
\text { - Planning and search strategies }\end{array}$ & $\begin{array}{l}\text { 8 Machine learning } \\
\text { - General } \\
\text { - Supervised learning } \\
\text { - Unsupervised learning } \\
\text { - Mixed methods } \\
\text { - Deep learning }\end{array}$ \\
\hline $\begin{array}{l}\text { 3 Big Data Systems } \\
\text { - Problems of scale } \\
\text { - Big data computing architectures } \\
\text { - Parallel computing frameworks } \\
\text { - Distributed data storage } \\
\text { - Parallel programming } \\
\text { - Techniques for Big Data applications } \\
\text { - Cloud computing } \\
\text { - Complexity theory } \\
\text { - Software support for Big Data applications }\end{array}$ & $\begin{array}{l}\text { 9 Programming, data structures and algorithms } \\
\text { - Algorithmic thinking and problem solving } \\
\text { - Programming } \\
\text { - Data structures } \\
\text { - Algorithms } \\
\text { - Basic complexity analysis } \\
\text { - Numerical computing }\end{array}$ \\
\hline $\begin{array}{l}\text { 4 Computing and Computer Fundamentals } \\
\text { - Basic computer architecture } \\
\text { - Storage systems fundamentals } \\
\text { - Operating system basics } \\
\text { - File systems } \\
\text { - Networks } \\
\text { - The web and web programming } \\
\text { - Compilers and interpreters }\end{array}$ & $\begin{array}{l}\text { 10 Software development and maintenance } \\
\text { - Software design and development } \\
\text { - Software testing }\end{array}$ \\
\hline $\begin{array}{l}\text { 5 Data Acquisition, Management, and Governance } \\
\text { - Data acquisition } \\
\text { - Information extraction } \\
\text { - Working with various types of data } \\
\text { - Data integration } \\
\text { - Data reduction and compression } \\
\text { - Data transformation } \\
\text { - Data cleaning } \\
\text { - Data privacy and security }\end{array}$ & $\begin{array}{l}\text { 11 Professionalism } \\
\text { - Continuing professional development } \\
\text { - Communication } \\
\text { - Teamwork } \\
\text { - Economic considerations } \\
\text { - Privacy and confidentiality } \\
\text { - Ethical considerations } \\
\text { - Legal considerations } \\
\text { - Intellectual property } \\
\text { - On automation }\end{array}$ \\
\hline $\begin{array}{l}\text { 6 Data Mining } \\
\text { - Proximity measurement } \\
\text { - Data preparation } \\
\text { - Information extraction } \\
\text { - Cluster analysis } \\
\text { - Classification and regression } \\
\text { - Pattern mining } \\
\text { - Outlier detection } \\
\text { - Time series data } \\
\text { - Mining web data } \\
\text { - Information retrieval }\end{array}$ & \\
\hline
\end{tabular}




\section{Cluster of Competencies}

- For the purposes of this research paper, the eleven (11) ACM Task Force Report Competencies were clustered into seven (7) competencies as follows: 1) Computing fundamentals, 2) Data management, governance, and privacy, 3) Data visualization, 4) Machine learning, 5) Data mining, Big data, 6) Data Science in context, and 7) Math and Statistics.

- Table 5 presents the competencies used in this research, the corresponding competencies presented in the 2021 ACM Task Force Report, and sample courses for each competency.

- This bottom-up approach was used after a careful evaluation of the curriculum requirements for the graduate programs in the 228 colleges examined. It was determined that several of the competencies presented in the 2021 ACM Task Force report should be combined to align more directly with current Data Science degree programs.

- Table 5 below maps the seven competencies used in this research to the 2021 ACM Data Science Task Force report competencies.

Table 5: Competencies, Equivalent ACM Competencies, \& Sample Courses

\begin{tabular}{|c|c|c|}
\hline Competencies & $\begin{array}{c}\text { ACM Data Science Task Force Report } \\
\text { Competencies }\end{array}$ & Sample Courses \\
\hline Computing Fundamentals & $\begin{array}{l}\text { 4.Computing and Computer Fundamentals } \\
\text { 9. Programming, data structures and algorithms } \\
\text { 10.Software development and maintenance }\end{array}$ & $\begin{array}{l}\text { SQL Programming, Introduction to Programming, } \\
\text { Algorithms, Data Structures, Object Oriented } \\
\text { Programming, Software Engineering, Systems } \\
\text { Analysis and Design, Human-Computer Interaction }\end{array}$ \\
\hline $\begin{array}{l}\text { Data Management, } \\
\text { Governance, Privacy }\end{array}$ & $\begin{array}{l}\text { 5.Data Acquisition, Management, and Governance } \\
\text { 7.Data Privacy, Security, Integrity, and Analysis } \\
\text { for Security } \\
\text { 11.Professionalism }\end{array}$ & $\begin{array}{l}\text { Data Warehousing, SQL, Databases, Security, } \\
\text { Fraud Detection, Network Security, Ethics }\end{array}$ \\
\hline Data Visualization & 1.Analysis and Presentation & Data Visualization \\
\hline Machine Learning & $\begin{array}{l}\text { 8.Machine learning } \\
\text { 2.Artificial Intelligence }\end{array}$ & $\begin{array}{l}\text { Machine Learning, Data Modeling, Artificial } \\
\text { Intelligence, Deep Learning }\end{array}$ \\
\hline Data Mining, Big Data & $\begin{array}{l}\text { 6.Data Mining } \\
\text { 3.Big Data Systems }\end{array}$ & $\begin{array}{l}\text { Data mining, Data modeling, systems analysis, Big } \\
\text { Data, Data munging }\end{array}$ \\
\hline Data Science in Context & 11.Professionalism & $\begin{array}{l}\text { Capstone, Internship, Senior Project, courses in } \\
\text { disciplines such as physics, biology, chemistry, the } \\
\text { humanities, or other areas }\end{array}$ \\
\hline Math and Statistics & 9.Programming, data structures and algorithms & $\begin{array}{l}\text { Calculus, discrete structures, probability theory, } \\
\text { elementary statistics, advanced topics in statistics, } \\
\text { and linear algebra. }\end{array}$ \\
\hline
\end{tabular}

\subsection{Data Analysis}

As part of the program profile analysis, department/school and major clusters were initially coded by two researchers. The evaluations were compared and Cohen's Kappa value was calculated to measure inter-coder reliability. The Cohen's Kappa value for the department/school's name clusters was .86 and for the major clusters was .92. The Pivot table feature in Excel was used to analyze the data, and the Excel graph feature was used to visualize the results. 


\section{RESUlTS}

\subsection{Overview of Master level of Data Science.}

In this context, many universities in the United States have successively opened master's programs in data science. This research will provide an overview of the current status of data science disciplines, mainly through the academic majors, credits, core courses, and the fields mentioned.

Some status in the results are consistent with common sense. For example, data science is still focusing on science domain, public institutions are generally larger than private institutions, and private colleges prefer to offer online courses.

\subsubsection{Types of College and Majors}

In the American university system, private and public institutions play a pivotal role. This is a characteristic of American universities, and because of the different systems, schools have different views and emphasis on specific programs. In this study, the results showed that public colleges generally offer more data science graduate programs (38) than private colleges (26). But the proportion of data science majors in public colleges (25.5\%) is lower than that of private colleges (32.9\%). The overall consistency in different majors is the same. They all focus on data science, business analytics, and data analytics. In particular, public colleges' mathematics and statistics programs are significantly higher than those offered by private colleges.

Table 6: Types of Colleges and Majors

\begin{tabular}{lcccc}
\hline & Private & $\mathbf{\%}$ & Public & \% \\
\hline Data Science & 26 & $32.9 \%$ & 38 & $25.5 \%$ \\
Business Analytics & 12 & $15.2 \%$ & 29 & $19.5 \%$ \\
Data Analytics & 9 & $11.4 \%$ & 20 & $13.4 \%$ \\
IST* & 8 & $10.1 \%$ & 19 & $12.8 \%$ \\
Biomedical & 7 & $8.9 \%$ & 4 & $2.7 \%$ \\
Business Intelligence & 5 & $6.3 \%$ & 5 & $3.4 \%$ \\
Computer Science & 4 & $5.1 \%$ & 7 & $4.7 \%$ \\
Math/Statistics & 3 & $3.8 \%$ & 17 & $11.4 \%$ \\
Public Policy & 3 & $3.8 \%$ & 2 & $1.3 \%$ \\
Health Informatics & 2 & $2.5 \%$ & 7 & $4.7 \%$ \\
Big Data & 0 & $0.0 \%$ & 1 & $0.7 \%$ \\
\hline IST is an abbreviation
\end{tabular}

*IST is an abbreviation for Information Science and Technology

\subsubsection{Types of College and Degrees}

It can be seen from Table 7 that data science has an absolute advantage in favor of science. Only a few programs are about MA and MBA. Data Science programs seemed to be focused more on the sciences as the majority of the programs are designated Masters of Science degree programs.

Table 7: Degrees and Types of Colleges

\begin{tabular}{lcc}
\hline Degree & Private & Public \\
\hline MA & 3 & 4 \\
MBA & 3 & 5 \\
MS & 73 & 140
\end{tabular}




\subsubsection{Major and Department}

Although the distribution of degrees is concentrated on science degrees, the distribution of majors is not only focused on data science. From Table 8, it can be found that 62 majors are in data science, and 36 majors are in business analytics. This shows that the business major also attaches great importance to the development of data, and there are 7 similar business intelligence majors. 27 programs about information science and technology and 19 majors belong to Math and Statistics.

Table 8: Majors and Types of Degrees

\begin{tabular}{lccc}
\hline Major & MA & MBA & MS \\
\hline Big Data & 0 & 0 & 1 \\
Biomedical & 0 & 0 & 11 \\
Business Analytics & 1 & 4 & 36 \\
Business Intelligence & 0 & 3 & 7 \\
Computer Science & 2 & 0 & 9 \\
Data Analytics & 1 & 0 & 28 \\
Data Science & 1 & 1 & 62 \\
Health Informatics & 0 & 0 & 9 \\
Information Science and Technology & 0 & 0 & 27 \\
Math/Statistics & 1 & 0 & 19 \\
Public Policy & 1 & 0 & 4 \\
\hline
\end{tabular}

\subsubsection{Credit Profile Information}

The result of credit analysis (table 9) shows that there are only 4 programs in the 18-28 credit period. However, there are 115 programs with 30 credits required for program completion. Secondly, there are 38 majors that require 36 credits to graduate. There are 32 majors in the 31-35 section and 34 majors in the 37-68 section (In addition, three universities used 100-120 credits. After further analysis, credits here are not usually referred to as "credits", but more similar to the concept of units, so they are not included in this section. ). From the analysis point of view, the most mainstream graduate program required credits are 30 credits and 36 credits.

Table 9: Majors and Credits

\begin{tabular}{ccccccccccccc}
\hline $\begin{array}{c}\text { Credit } \\
\text { Major }\end{array}$ & $\begin{array}{c}\text { Big } \\
\text { Data }\end{array}$ & Biomedical & $\begin{array}{c}\text { Business } \\
\text { Analytics }\end{array}$ & $\begin{array}{c}\text { Business } \\
\text { Intelligence }\end{array}$ & $\begin{array}{c}\text { Computer } \\
\text { Science }\end{array}$ & $\begin{array}{c}\text { Data } \\
\text { Analytics }\end{array}$ & $\begin{array}{c}\text { Data } \\
\text { Science }\end{array}$ & $\begin{array}{c}\text { Health } \\
\text { Informatics }\end{array}$ & $\begin{array}{c}\text { Information } \\
\text { Science and } \\
\text { Technology }\end{array}$ & $\begin{array}{c}\text { Math } \\
\text { Statistics }\end{array}$ & $\begin{array}{c}\text { Public } \\
\text { Policy }\end{array}$ & $\begin{array}{c}\text { Sum } \\
\text { Sum }\end{array}$ \\
\hline $18-28$ & 0 & 1 & 1 & 0 & 0 & 0 & 2 & 0 & 0 & 0 & 0 & 4 \\
30 & 1 & 5 & 20 & 4 & 8 & 13 & 33 & 3 & 14 & 12 & 2 & 115 \\
$31-35$ & 0 & 0 & 7 & 1 & 1 & 4 & 10 & 1 & 3 & 5 & 0 & 32 \\
36 & 0 & 2 & 5 & 3 & 1 & 7 & 10 & 3 & 3 & 2 & 2 & 38 \\
$37-68$ & 0 & 3 & 7 & 2 & 0 & 5 & 8 & 2 & 5 & 1 & 1 & 34 \\
\hline
\end{tabular}

\subsubsection{Instruction Modal and Majors}

Although online courses have been promoted in recent years, the results of this research have found that in the field of graduate courses, face-to-face campus teaching is still dominant. Blended teaching and online teaching have not yet started. Even in the data science major, only 12 majors are taught purely online, and 5 are blended courses. Tabel 10 below depicts the majors and the mode of instruction. 
Table 10: Majors and Mode of Instruction

\begin{tabular}{lccc}
\hline Major & Campus & Online & Blended \\
\hline Data Science & 47 & 12 & 5 \\
Business Analytics & 31 & 3 & 7 \\
Data Analytics & 24 & 3 & 2 \\
Information Science and Technology & 24 & 2 & 1 \\
Math/Statistics & 19 & 1 & 0 \\
Biomedical & 8 & 2 & 1 \\
Computer Science & 8 & 1 & 2 \\
Business Intelligence & 6 & 4 & 0 \\
Health Informatics & 3 & 6 & 0 \\
Public Policy & 3 & 0 & 2 \\
Big Data & 1 & 0 & 0 \\
\hline
\end{tabular}

\subsubsection{Mode of Instruction and Type of College}

Table 11: Types of College and Mode of Instruction

\begin{tabular}{|c|c|c|c|c|c|c|}
\hline \multirow[t]{2}{*}{ Row Labels } & \multicolumn{2}{|c|}{ Campus } & \multicolumn{2}{|c|}{ Online } & \multicolumn{2}{|c|}{ Blended } \\
\hline & Number & Percentage & Number & Percentage & Number & Percentage \\
\hline Private & 57 & $72.1 \%$ & 15 & $19.0 \%$ & 7 & $8.9 \%$ \\
\hline Public & 117 & $78.5 \%$ & 19 & $12.8 \%$ & 13 & $8.7 \%$ \\
\hline
\end{tabular}

When the specific analysis is whether private colleges prefer online courses or public colleges prefer to teach online, Table 11 shows that there is no significant difference between the two types of colleges. Although the proportion of online courses in private colleges (19\%) is relatively higher, the overall number of programs is similar to public colleges. There are 15 online programs of private colleges, and 19 online programs from public colleges. If the blended model is also combined with online model, the proportion of private colleges using online forms is $27.9 \%$, and the number of public colleges is $21.5 \%$. In terms of proportion, private colleges are higher. In terms of absolute numbers, public schools still have an advantage in teaching on campus and a slight advantage in online teaching.

\subsubsection{Regions and Majors}

According to the regional distribution of the colleges and universities, we can analyze the situation of each major. From table 12, we can find that the data science majors have the most areas: 23 in the Northeast, 14 in the Midwest, 15 in the West, and 12 in the South. Business analytics has a similar trend. For a Math/Statistics major, 8 from Midwest and 7 from South is almost double the number of the Northeast region.

From another perspective, the four regions have no particular preference for the distribution of majors.

Table 12: Majors and Regions

\begin{tabular}{lcccc}
\hline Major & Northeast & Midwest & West & South \\
\hline Data Science & 23 & 14 & 15 & 12 \\
Business Analytics & 11 & 11 & 9 & 10 \\
Data Analytics & 11 & 5 & 3 & 10 \\
Information Science and Technology & 7 & 5 & 3 & 12 \\
Business Intelligence & 4 & 4 & 1 & 1
\end{tabular}




\begin{tabular}{lllll} 
Computer Science & 4 & 2 & 1 & 4 \\
Math/Statistics & 4 & 8 & 1 & 7 \\
Health Informatics & 3 & 4 & 1 & 1 \\
Public Policy & 2 & 1 & 1 & 1 \\
Big Data & 0 & 0 & 1 & 0 \\
Biomedical & 0 & 5 & 2 & 4 \\
\hline
\end{tabular}

\subsection{Data Science Development Direction Analysis}

From the previous overview of the characteristics of data science itself, the development of data science will definitely move in the direction of multidisciplinary integration.

\subsubsection{Competencies and Majors}

The analysis of competencies and majors presented that data science reached the highest number of competencies. The following are business analytics, data analytics, math/statistics, information science and technology, and computer science. Within the 228 targeted graduate programs, 177 programs required computing fundamentals, and 172 programs needed data management and relevant courses. Besides that, 157 programs required math and statistics, 139 programs needed data science knowledge, and 125 programs had data mining and big data courses (See the details in table 13).

\begin{tabular}{lcccccccc}
\multicolumn{1}{c}{ Table 13: Competencies and Majors } \\
\hline & $\begin{array}{c}\text { Computing } \\
\text { Fundamentals }\end{array}$ & $\begin{array}{c}\text { Data } \\
\text { Management, } \\
\text { Governance, } \\
\text { Privacy }\end{array}$ & $\begin{array}{c}\text { Data } \\
\text { Visualization }\end{array}$ & $\begin{array}{c}\text { Machine } \\
\text { Learning }\end{array}$ & $\begin{array}{c}\text { Data } \\
\text { Mining, } \\
\text { Big } \\
\text { Data }\end{array}$ & $\begin{array}{c}\text { Data } \\
\text { Science } \\
\text { in } \\
\text { context }\end{array}$ & $\begin{array}{c}\text { Sensors } \\
\text { and } \\
\text { Sensor } \\
\text { Networks }\end{array}$ & $\begin{array}{c}\text { Math } \\
\text { and } \\
\text { Statistics }\end{array}$ \\
\hline Data Science & 52 & 41 & 20 & 23 & 35 & 49 & 1 & 52 \\
Business Analytics & 32 & 33 & 12 & 7 & 30 & 21 & 0 & 29 \\
Data Analytics & 22 & 20 & 11 & 6 & 20 & 18 & 0 & 15 \\
Math/Statistics & 18 & 14 & 0 & 1 & 7 & 9 & 0 & 18 \\
IST* & 14 & 22 & 2 & 3 & 18 & 19 & 2 & 10 \\
Computer Science & 11 & 9 & 4 & 1 & 4 & 3 & 0 & 9 \\
Business Intelligence & 9 & 10 & 2 & 0 & 2 & 4 & 0 & 5 \\
Biomedical & 7 & 9 & 1 & 2 & 3 & 5 & 1 & 11 \\
Health Informatics & 7 & 9 & 1 & 0 & 3 & 6 & 0 & 6 \\
Public Policy & 4 & 4 & 2 & 0 & 2 & 4 & 1 & 2 \\
Big Data & 1 & 1 & 1 & 1 & 1 & 1 & 0 & 0 \\
No. of Colleges & $\mathbf{1 7 7}$ & $\mathbf{1 7 2}$ & $\mathbf{5 6}$ & $\mathbf{4 4}$ & $\mathbf{1 2 5}$ & $\mathbf{1 3 9}$ & $\mathbf{5}$ & $\mathbf{1 5 7}$ \\
\hline
\end{tabular}

*IST is an abbreviation for Information Science and Technology

\subsubsection{Master Level Universities Distribution by Regions}

Based on the population distribution in the United States, Figure 1 shows that the darker red dots represent the highest population in the area. The red dots represent the location of the Northeast Data Science Graduate Colleges, the blue dots represent the Midwest Colleges, the green dots represent the Western Colleges, and the purple dots represent the Southern Colleges (See Figure 1).

The distribution results show more data science colleges in areas with high population density. In the Midwest, data science collges are mainly concentrated in the traditional industrial areas of the Great Lakes, in the west, data science colleges are distributed in the IT industry area, and the south, data science colleges are mostly located in Texas. 

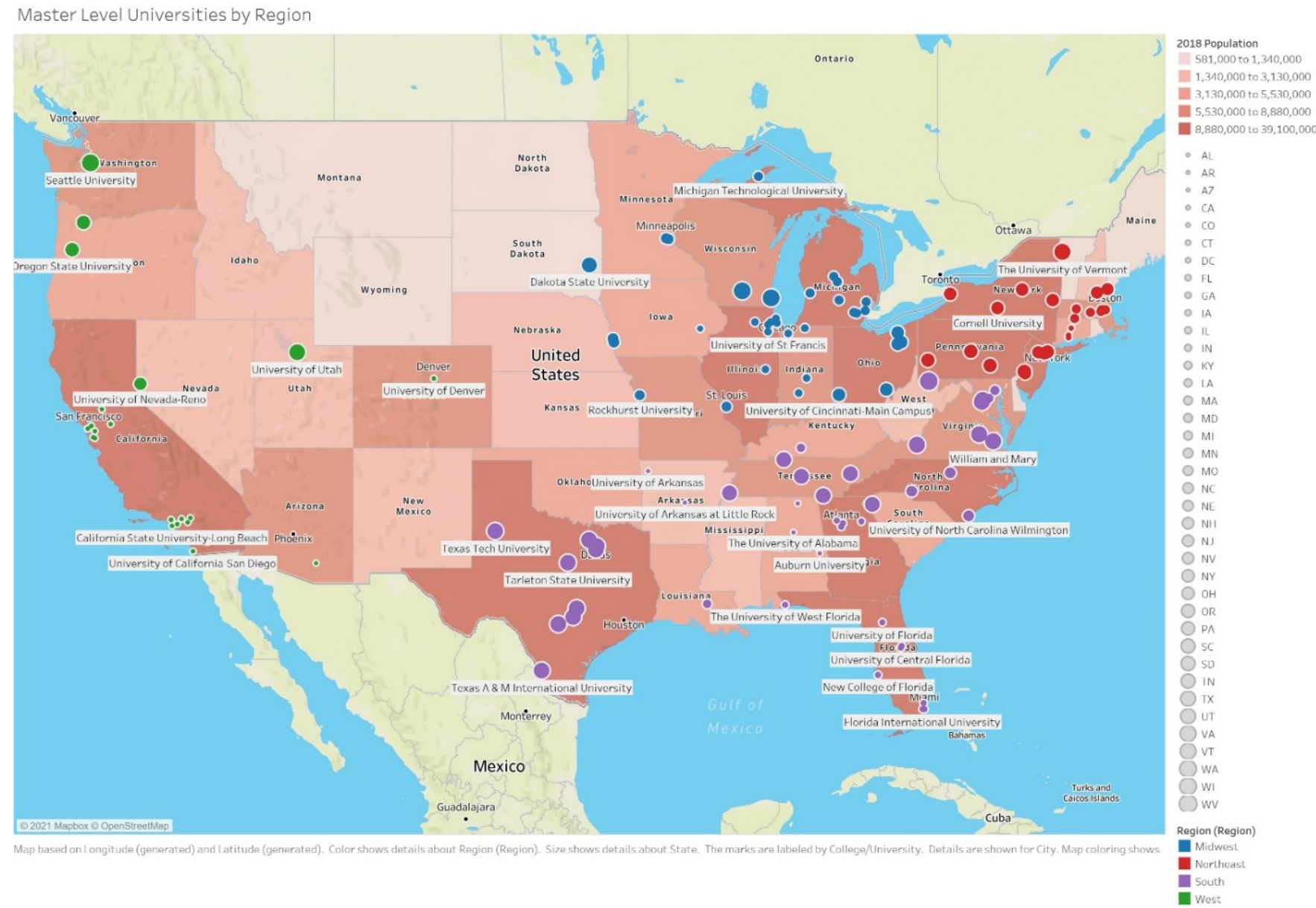

Fig. 1. Master Level Universities Distribution by Region

\subsubsection{Population and Universities Mode Distribution}

Looking at the distribution of public and private colleges in the population distribution, the red dots represent public colleges, and the blue dots represent private colleges. The darker the red block is, the greater the number of population represented in the area. It can be found that most areas are still dominated by public institutions, while private institutions are mainly in the Northeast and the Great Lakes Industrial Zone. 


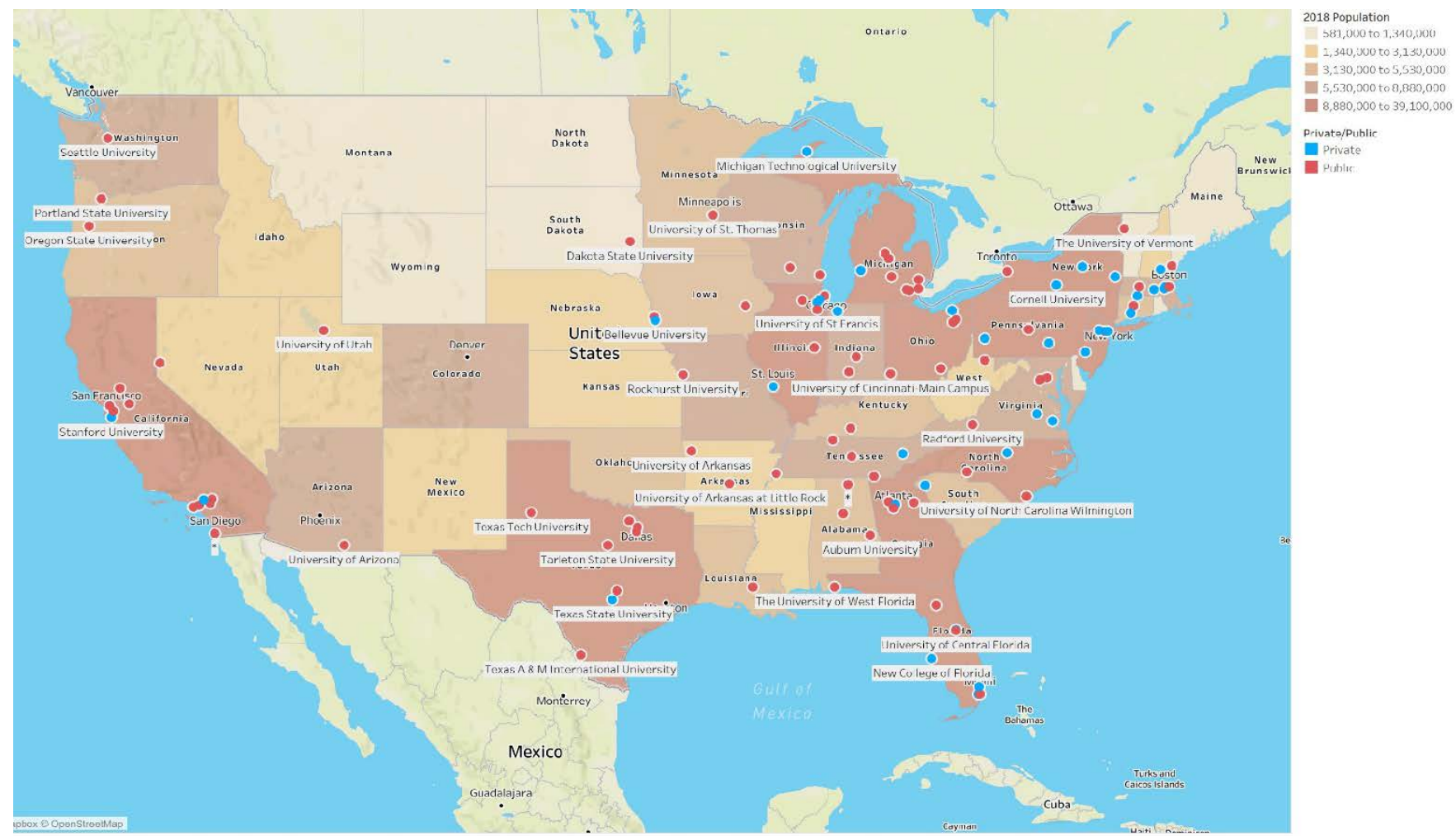

Fig. 2. Universities Distribution by Mode

\section{DISCUSSION}

An analysis of 228 data science graduate programs in the United States shows that the field of data science education is undergoing change and is also full of opportunities. These key aspects revealed by the analysis are discussed in the following sections.

\subsection{Discussion related to data science graduate program}

At the graduate level, data science has more than 228 related majors in the United States. And from the perspective of geographical distribution, there are relevant graduate majors to choose from in the Northeast, Midwest, or South and West. The credits of mainstream graduate courses are concentrated in 30-36 credits range, which means that the academic system may generally be between one and a half to two years, and the primary degree is still based on Master of Science. However, business students can also find corresponding MBA or MA majors to pursue. It should be noted that even if they choose the business programs, they still need a specific programming language foundation and data analysis skills. Data science also appears in health and biomedicine, which may be due to the demand for data in modern medicine.

The results from this study differe from Duaa Bukhari (2020), which focuses on analyzing the core courses [6]. In this research, the focus was on the breadth analysis of disciplines, and unified the data management course with governance and privacy as a rule-based course. In Soria-Comas \& Domingo-Ferrer's article, database management is proposed separately and classified as a technical data science course. The results from this study also show that the intensity of government 
policy discussions [10] is also a reason for the increase in the number of institutions setting up such courses.

There are also some specialties in government policies and information systems, which shows that with the popularization of big data technology, many industries have begun to attach importance to and need professional data scientists. This also puts forward a direction for graduate education: while studying this major, people must pay great attention to the development of the interdisciplinary field. The application of data science will basically be reflected in the interdisciplinary field. At present, there is still a lack of unified data science evaluation standards, which also leads to the lack of uniformity in the course names of many majors, and it will also limit the choice of graduate majors for undergraduate students.

\subsection{Findings}

There are 228 master-level programs in this study and 177 different universities in total. Interestingly, there are 39 universities having more than 1 graduate program on the data science domain. In another way to say, there are $22 \%$ of universities having two different master level programs from different departments.

Data science is an applied major that combines multiple disciplines. Although the subject focuses is different, it can be found from Table 13 that these subjects basically require knowledge of Computing fundamentals, which means that most of them need programming skills and data analysis capabilities. Mathematics and statistics are very important. Even if there is a system or platform to assist data analysis in the future, reading data reports requires knowledge of mathematics and statistics.

Analysis shows that many majors in data visualization and machine learning are already being developed, and these two fields may be potential areas for data science graduate programs in the next 5-10 years. Woodward, Figueiredo, and Guimaraes (2006) pointed out that high-technology plant openings mainly by west coast, northeast coast, and Great Lakes Industrial Zone [11]. Friedman \& Silberman (2003) presented university technology transfer between academic and industry domain. They emphasized the importance of spillover effects and externalities due to the vast and growing technology industry in the surrounding areas of the university. Policies that attract the technology industry and private sector research will have spillover effects and feedback effects through increased university technology transfer [12]. In other words, universities, majors, and industries in the region interact with each other. As a relatively new subject, data science is also a frontier subject of science and technology, and it is more concerned about the distribution of majors in the region. In view of the distribution of data science institutions, both public and private are relatively balanced, so scholars do not need to be overly entangled with geographical factors. However, there are too few online courses offered, which is a more major problem. Only 34 programs are pure online education, and the proportion of 228 analysis samples is too small. In the case that the epidemic has not been effectively controlled, the relevant data science majors should increase the development and use of online courses. Even if the epidemic is under control, some

people still need to receive advanced training, and factors such as work and family will make it difficult to travel. Increasing the proportion and number of online courses has become very worthwhile and necessary

\section{CONCLUSION}

The results of this study show that graduate programs in data science are booming and in transition. Public and private universities all over the United States have graduate programs in data 
science. This research also shows that data science has shown the alternative of interdisciplinary and multidisciplinary integration at the graduate level, so how to train multi-level and multi-type data science professionals needs to be studied in time. In order to meet the needs of more fields in society, it brings challenges and possibilities to the existing settings of data science application graduate courses.

\subsection{Study Limitation}

This study has some limitations, including the timeliness of the data. The data science program is still under development and adjustment. The name and content of some postgraduate courses in some schools are still constantly being revised and adjusted. In order to avoid confusion, some inaccessible page data has not been captured.

\subsection{Future Research}

Future research can be combined with other data, such as government policies, the layout of different industries, and the economic level of the institute. Researchers can also collect more data to conduct interdisciplinary analysis. For example, from undergraduate to graduate professional consistency and so on. Accreditation of data science graduate programs is lacking, and most of the programs have not yet a unified accreditation for certification. All fields and industries need to establish standards for public trust and growth. Driven by the surge in demand for data scientists, the progress made by the ACM Data Science Task Force on defining data science competencies, and the inquiries about data science accreditation, ABET is developing accreditation standards for undergraduate data science courses[13]. Similarly, ABET should have accreditation standards for graduate data science courses in the future.

The concept of "communication/privacy/professionalism/ethics" has had a huge impact on society in the era of increasing data explosion. No matter how skilled the technicians are, if ethics and privacy are not considered, these people can cause great harm. This could also be the subject of future research.

\section{REFERENCE}

[1] P. Paul, and P.S. Aithal, "Computing Academics into New Age Programs and Fields: Big Data Analytics \& Data Sciences in Indian Academics-An Academic Investigation,” IRA-International Journal of Management \& Social Sciences, vol. 10, pp. 107-118, 2018.

[2] R. Tang, and W. Sae-Lim, "Data science programs in US higher education: An exploratory content analysis of program description, curriculum structure, and course focus.” Education for Information, vol. 32, pp. 269-290, 2016.

[3] I. Y. Song and Y. Zhu, "Big data and data science: opportunities and challenges of iSchools" Journal of Data and Information Science, vol. 2, pp. 1-18, 2016.

[4] A.P. Murillo, and K. M. Jones, "The development of an undergraduate data curriculum: A model for maximizing curricular partnerships and opportunities,” In International Conference on Information (pp. 282-291). Springer, Cham, 2018.

[5] J.A. White, D.P. Gaver, R.J. Butera, et al. "Core Competencies for Undergraduates in Bioengineering and Biomedical Engineering: Findings, Consequences, and Recommendations,” Ann Biomed Eng vol. 48, pp. 905-912, 2020.

[6] D. Bukhari, "Data Science Curriculum: Current Scenario,” International Journal of Data Mining \& Knowledge Management Process (IJDKP), vol. 10, 2020.

[7] J. Kim, "Who is teaching data: meeting the demand for data professionals," Journal of Education for Library and Information Science, vol. 57, pp.161-173, 2016.

[8] Hu, X., Chu, S. K. W., Downie, J. S., \& Lee, C. W. Y. (2017). Data Science as an Emerging Discipline: The Roles of iSchools in the Era of Big Data. In iConference: Workshop 4b-Information Science to Data Science: New Directions For iSchools.

[9] EMC2. Career of the Future: Data Scientist Study Results Infographic [EB/OL].[2014-09-23]. Https://www.pinterest.com/pin/27092035228243693/

[10] Soria-Comas, J., \& Domingo-Ferrer, J. (2016). Big data privacy: challenges to privacy principles and models. Data Science and Engineering, $1(1), 21-28$.

[11] Woodward, D., Figueiredo, O., \& Guimaraes, P. (2006). Beyond the Silicon Valley: University R\&D and high-technology location. Journal of urban economics, 60(1), 15-32. 
[12] Friedman, J., \& Silberman, J. (2003). University technology transfer: do incentives, management, and location matter? The Journal of technology transfer, 28(1), 17-30.

[13] Blair, J. R., Jones, L., Leidig, P., Murray, S., Raj, R. K., \& Romanowski, C. J. (2021, March). Establishing ABET Accreditation Criteria for Data Science. In Proceedings of the 52nd ACM Technical Symposium on Computer Science Education (pp. 535-540). 